\title{
EEN VOORONTWERP VAN EEN WET OP DE JAARREKENING VAN ONDERNEMINGEN
}

\author{
door Prof. A. M. van Rietschoten
}

Het rapport van de Commissie Verdam, dat op 26 november 1964 aan de Minister van Justitie is aangeboden, is in januari 1965 gepubliceerd onder de titel: Herziening van het Ondernemingsrecht.

Hetgeen het rapport bevat over de jaarverslaggeving van de onderneming vormt een essentieel gedeelte van de inhoud, in overeenstemming met de opdracht van de Commissie.

Het is het eerste onderwerp, krachtens de inleiding van het rapport. Voor dit artikel beperken wij ons tot dit belangrijke onderdeel.

Unaniem heeft de Commissie zich gesteld achter een voorstel voor een ontwerp van wet op de jaarrekening van ondernemingen, behoudens enkele bezwaren van sommige leden tegen enkele der voorgestelde artikelen. Gezien de samenstelling van de commissie en de belangstelling, welke sinds enkele jaren voor dit onderwerp bestaat, moet hieraan de nodige aandacht worden besteed. Het zou nu binnen enkele jaren wel eens tot wettelijke bepalingen van de voorgestelde strekking blijken te kunnen komen.

De verschillende onderwerpen, waarover het oordeel van de Commissie zich uitstrekt ter zake van de verslaggeving worden hieronder ter sprake gebracht. Wij doen dit in dezelfde indeling als die van Hoofdstuk IV van het rapport, te weten: de verslaggeving

de publiciteit en

de sanctie.

\section{De verslaggeving}

De Commissie concludeert, dat de wettelijke bepalingen, regelende de inhoud van de verslaggeving, zoals die voor de N.V. is neergelegd in art. 42 W.v.K., onvoldoende zijn.

Hoewel nu in het nieuwe B.W. in artikel 2.3.3.13 de regeling terzake van de inhoud en inrichting van de verslaggeving wordt overgelaten aan een algemene maatregel van bestuur, adviseert de Commissie tot een andere keuze. Zij staat een regeling bij de wet in een aantal vrij algemeen geformuleerde bepalingen voor, welke, zo schrijft zij, enerzijds de ondernemingen in alle duidelijkheid voorhouden aan welke normen de verslaggeving dient te voldoen, doch anderzijds genoeg speelruimte laten om de uitvoering aan te passen aan de omstandigheden van elke bedrijfstak.

$\mathrm{Zij}$ duidt deze weg als een tussenweg aan. Naar ons oordeel kunnen in dit voorstel vele voordelen worden gezien in vergelijking met andere mogelijkheden.

De ondernemingsbesturen kunnen blijk geven in staat te zijn door doelmatige nakoming van hetgeen blijkens het voorstel de bedoeling is, verdergaande regelingen onnodig en daarmee ongewenst te maken. De sanctie van verdergaande precisering der verplichtingen door de overheid, zal slechts worden toegepast ten aanzien van diegenen, van wie een hoog orgaan van de rechterlijke macht, de on- 
dernemingskamer van het Hof te Amsterdam, vaststelt dat aan de wettelijke voorschriften niet is voldaan. Daarmee wordt de autonomie der ondernemingen zoveel als in het algemeen belang toelaatbaar geacht, in stand gehouden. De zeer langdurige, gunstige ervaring op het terrein van deze aangelegenheden, die in Nederland gezegd mag worden te bestaan, wordt hiermede op goede wijze erkend, terwijl zij tevens een goede verwachting omtrent de werking der voorgestelde bepalingen ruimschoots toelaat.

Daarenboven moet, zoals de Commissie schrijft, de openbare behandeling, zoals een wet vereist, hier van groot belang worden geacht, zomede de grotere waarborgen voor continuïteit dan een algemene maatregel van bestuur geeft. Daaraan zou nog wel kunnen worden toegevoegd, dat de beslissing aan de rechterlijke macht verblijvende, niet politiek wordt beïnvloed.

Bovendien wijst de Commissie er op, dat met de beslissing in handen van een orgaan van de rechterlijke macht, het vragen van een oordeel, anders dan bij wijze van burgerrechtelijk proces niet mogelijk is. Bij toepassing van een orgaan van de uitvoerende macht, zou op grond van de ervaring zeker moeten worden verwacht, dat vooraf advies van het tot sanctie bevoegde overheidsorgaan zou worden gevraagd en verkregen. Naar sommiger mening zou dat ook gewenst zijn. Vele anderen zien zwaarderwegende nadelen. Daaronder de belangrijk groter dirigerende invloed van het overheidsorgaan, alsmede de verwachting van snel in detaillering toenemende voorschriften. Afgezien van de daarmee snel toenemende kosten van nakoming en toezicht, moet tevens een formelere nakoming worden gevreesd. Met name daardoor moet worden verwacht, dat met het sterk gedetailleerde voorschrift het doel van de open verslaggeving niet beter zou worden bereikt. Daaronder toch valt mede het afdwingen van meerdere openheid van hen, die daartoe niet bereid zijn.

Gaan wij nu nader in op hetgeen in het voorontwerp van een wet op de jaarrekening van ondernemingen wordt bepaald, voorzover het gaat om voorschriften voor de verslaggeving.

Het voorontwerp bestaat uit de volgende hoofdstukken:

I. Algemene bepalingen

II. Bepalingen omtrent de balans en de toelichting

III. Bepalingen omtrent de winst-en verliesrekening en de toelichting

IV. Gedingen omtrent jaarrekeningen

V. Slotbepalingen

De aan de verslaggeving te stellen eisen worden omschreven in de hoofdstukken I, II en III, waarbij de algemene bepalingen, vervat in hoofdstuk I, de belangrijkste zijn.

De voorschriften zullen toepasselijk zijn voor alle naamloze vennootschappen, open zowel als besloten, grote zowel als kleine, zo ook voor alle coöperatieve verenigingen, onderlinge verzekeringmaatschappijen, alsmede voor elke landbouwkredietbank, in de zin van artikel 1 , eerste lid onder c, van de wet toezicht kredietwezen, ook indien zij geen coöperatieve vereniging is.

Onder de jaarrekening wordt verstaan: de balans en winst- en verliesrekening met als bijlage de toelichting op deze stukken, zowel in de vorm waarin zij door het bestuur der onderneming zijn opgemaakt, als in de vorm, waarin zij door het 
bevoegde orgaan zijn vastgesteld (bij de N.V.) of goedgekeurd (bij de coöperatieve verenigingen).

Het is van belang op te merken, dat de voorschriften kunnen worden nagekomen, hetzij door vermelding der vereiste gegevens in de balans resp. in de winsten verliesrekening, dan wel in de toelichting op de balans of in de toelichting op de winst- en verliesrekening. Tezamen vormen die stukken de jaarrekening. Op blz. 55 zegt het rapport o.m. ,een scherpe grens tussen hetgeen in de balans thuisbehoort, en hetgeen in de toelichting kan worden vermeld, is moeilijk te trekken". Die scherpe grens kan dan ook heel wel worden gemist.

De artikelen 2 en 3 vormen de kern van de wet.

Artikel 2. De jaarrekening geeft met inachtneming van de bepalingen van deze wet een zodanig inzicht, dat een verantwoord oordeel kan worden gevormd omtrent het vermogen en de rentabiliteit van de onderneming, alsmede omtrent haar solvabiliteit en liquiditeit.

Artikel 3. 1. De balans met de toelichting daarop geeft getrouw en stelselmatig de grootte en de samenstelling van het vermogen van de onderneming op het einde van het boekjaar weer.

2. De winst- en verliesrekening met de toelichting daarop geeft getrouw en stelselmatig de grootte en de samenstelling van het resultaat van de onderneming over het boekjaar weer.

Het is belangrijk, dat uitgaande boven de voorschriften, omtrent de posten van de jaarrekening en derzelver detaillering en waardering, eerst wordt aangegeven wat met de jaarrekening moet worden bereikt, wil zij een wettige jaarrekening zijn.

Er is een grote mate van overeenstemming tussen de strekking van de gestelde algemene vereisten en die, welke destijds (1955) werden genoemd in het rapport van de Commissie jaarverslaggeving van de Werkgeversverbonden. De formulering verschilt, en de commissie heeft met haar formulering nog wel probleem gehad. Zij schrijft thans in de toelichting op de artikelen 2 en 3 o.m.: „Artikel 2 stelt daarbij als doel, dat men zich op grond van de jaarrekening een verantwoord, dat wil zeggen goed gefundeerd, zij het ook noodzakelijkerwijze niet volledig, oordeel kan vormen omtrent het vermogen en de rentabiliteit van de onderneming, alsmede van haar solvabiliteit en liquiditeit."

Hier komt naar ons oordeel tot uitdrukking, dat de commissie het ,,verantwoorde oordeel" ziet in het verband van de functionele plaats van degenen tot wie de verslaggeving wordt gericht. Het is belangrijker, dat zij betrouwbaar dan dat zij uitvoerig, laat staan volledig, worden ingelicht. In die betekenis kan de toelichting van de commissie goed voldoen; al is zij wat kort. In dezelfde toelichting wordt gezegd, dat de term vermogen zowel wordt gebruikt voor de actiefzijde als voor de passiefzijde van de balans. Wij dachten, dat zulks niet gebruikelijk was en wij zouden dan ook de voorkeur hebben gegeven aan de formulering: de grootte, de samenstelling en de aanwending van het vermogen. Dan zou zonder meer begrippen te hanteren en met gebruik van dezelfde termen worden verkregen, dat de passiefzijde en actiefzijde afzonderlijk worden genoemd.

De bewoording van de vereisten, vermeld in artikel 3, vraagt ook verder nog de aandacht. Een getrouw beeld van de grootte en samenstelling van het vermogen 
en van de grootte en samenstelling van het resultaat, kan een duidelijke aanwijzing heten. Maar wat is het vereiste van getrouw en stelselmatig? De aanduiding is ongebruikelijk en daardoor niet duidelijk. De Commissie heeft geen toelichting gegeven op de formulering, welke zij hier heeft gekozen.

Dat is jammer, omdat men dan nu naar de bedoeling van de Commissie moet raden.

Wij lezen in het voorgestelde achtereenvolgens, welk doel met de jaarrekening moet worden bereikt (artikel 2), uit welke stukken zij moet bestaan en welk gegeven elk dier stukken moet opleveren (artikel 3), welke eisen in beginsel aan hun uitvoerigheid worden gesteld (artikel 4), dat naar vaste grondslagen van waardering moet worden gewerkt en waaraan de grondslagen moeten voldoen (artikel 5). Wat bedoelt de Commissie dan met het woord stelselmatig in artikel 3 ? Over het stelsel wordt eerst gesproken in artikel 5. In artikel 3 is nog pas de eerste aanduiding van het middel aan de orde. Daar komt een vereiste van stelselmatigheid nog niet erg tot zijn recht.

In artikel 5 zou de plaats zijn geweest voor de bepaling, dat de jaarrekening stelselmatig en naar bepaalde waarderingsgrondslagen moet worden samengesteld.

Ten aanzien van de beginselen der detaillering in de jaarrekening stelt de commissie terecht, dat voor de beoordeling van een jaarrekening van groot belang is de mate van homogeniteit van de waarden, die in één post gezamenlijk op de balans of op de winst- en verliesrekening verschijnen.

In artikel 4 wordt dan ook bepaald:

„Samenvoeging van gegevens tot één post op de balans of de winst- en verliesrekening zonder ontleding daarvan in de toelichting geschiedt slechts voor zover daardoor het inzicht dat de jaarrekening behoort te geven, niet wordt belemmerd."

Toch kan naar het oordeel van de commissie deze zaak niet met deze algemene bepaling voldoende worden geregeld. $\mathrm{Zij}$ geeft een uitwerking van dit beginsel voor de balans in hoofdstuk II, artikel 9 - 16 ten aanzien van de activa en $17-23$ voor de passiva en voor de winst- en verliesrekening in Hoofdstuk III de artikelen $24-26$.

Wij gaan die bepalingen nu voorbij om te zien, wat er aan verdere algemene bepalingen wordt geboden.

Eerst volgen dan de waarderingsgrondslagen voor de activa en de passiva. Het voorontwerp duidt ze wel aan, maar bepaalt ze niet. Het zegt in artikel 5:

1. De grondslagen waarop de waardering van de activa en passiva rust, voldoen aan normen die in het maatschappelijk verkeer als aanvaardbaar worden beschouwd.

3. De toelichting op de balans geeft een uiteenzetting omtrent de waarderingsgrondslagen.

In beginsel is hiermede het wettelijk systeem van 1928 gehandhaafd. De commissie licht toe, dat het artikel geschreven is met het oog op het tegengaan van excessen op het gebied van het vormen van stille en geheime reserves. Het is begrijpelijk dat de commissie aan de gebruiken op dat punt iets meende te moeten doen, op grond van de algemene doelstelling, dat de jaarrekening een zodanig inzicht moet verschaffen, dat een verantwoord oordeel kan worden gevormd omtrent het vermogen en het resultaat van de onderneming ... (art. 2). Het kan 
nauwelijks zijn, dat de verbetering in de bewoording van het ontworpen artikel 5 vergeleken bij artikel 42 lid 1 W.v.K. het gewenste effect ten volle kan doen verwachten.

Er zal van de doelmatiger wijze van ingrijpen, zoals door middel van de ondernemingskamer wordt nagestreefd, een belangrijke bijdrage op dit punt moeten worden verwacht; mogelijk in de meest belangrijke mate bij wijze van preventieve invloed. Verder in dit stuk zal er gelegenheid zijn daar nog iets naders van te zeggen.

Voor de vakman kan het geen verrassing zijn, dat de commissie de gevolgen van wijziging in de waarderingsgrondslagen met zoveel woorden noemt (artikel 5 lid 2) en er een algemene bepaling aan wijdt. Door voor te schrijven, dat de invloed op de jaarrekening van een wijziging in de waarderingsgrondslagen moet worden vermeld, is de onveranderlijkheid der waarderingsgrondslagen, zolang geen vermelding van de gevolgen plaats vindt, in de voorschriften begrepen.

De toelichting bij artikel 6 geven wij hier ten volle:

„Een van de belangrijkste oorzaken, waardoor het beeld dat de jaarrekening geeft, vertroebeld wordt, is de vorming van stille en geheime reserves. Het ontwerp keert zich daartegen o.a. met het reeds besproken artikel 5, dat de zuiverheid der waarderingsgrondslagen beoogt en met artikel 20 , dat voorschrijft voorzieningen tegen bepaalde risico's en met het oog op concrete verplichtingen af zonderlijk te vermelden.

Artikel 6 completeert dit beeld door voor te schrijven, dat reserveringen en onttrekkingen aan de reserves ten laste, respectievelijk ten gunste van het jaarresultaat niet in het geheim mogen geschieden, maar dat zij worden vermeld en toegelicht."

Hier spreekt naar ons oordeel de commissie zich het duidelijkst uit ter zake van een der belangrijkste struikelblokken voor het bereiken van een doelmatige verslaggeving. Het zal moeten worden afgewacht wat hier door tegenstanders nog op zal kunnen worden afgedongen, alvorens een wet de inhoud zal hebben van dit voorontwerp. In verband met dit onderwerp is het mogelijk gepast te verwijzen naar het rapport van een subcommissie van de C.A.B. van het N.I.v.A.: De gevolgen van stille en geheime reservering voor de goedkeuring der jaarrekening door de accountant (De Accountant, 68e jaargang, no. 9) en Mr. J. de Wilde, Stille en Geheime Reserves (M.A.B. 38e jaargang No. 6) en P. J. H. J. Bos onder dezelfde titel (M.A.B. 38e jaargang No. 9).

Tenslotte moet bij de bespreking der algemene bepalingen aandacht worden besteed aan het voorschrift de bezoldiging van ieder der commissarissen van de onderneming in de jaarrekening te vermelden (artikel 7). Hoewel er een hoofdstuk in het voorontwerp voorkomt, houdende bepalingen omtrent de winst- en verliesrekening en de toelichting, komt niet daarin maar onder de algemene bepalingen het genoemde voorschrift voor. Wij houden het er op, dat de reden hiervoor moet worden gezocht in de omstandigheid, dat dit voorschrift niet een uitwerking vormt van de algemene vereisten, waaraan de jaarrekening zal moeten voldoen (artikelen 2 en 3 ). Het voorschrift moet volgens de Commissie dienen als een belangrijke rem op het toekennen en handhaven van bezoldigingen, die onverantwoord hoog zijn. Bovendien wordt het billijk geacht dat de algemene vergadering van aandeelhouders zich er rekenschap van kan geven welke bedragen 
aan ieder der commissarissen worden toegedacht, omdat de bezoldiging aan commissarissen krachtens de statuten moet zijn toegekend.

Wat er nu ook van de argumentatie zij, mogen wij een tweetal opmerkingen bij deze bepaling en haar toelichting maken. De commissie heeft ons verrast met haar oordeel, dat de bepaling, dat de bezoldiging van ieder der commissarissen in de jaarrekening moet worden vermeld, niet betekent dat in de jaarstukken per commissaris wordt vermeld hoeveel zijn bezoldiging bedraagt. Men kan, zo zegt de commissie, volstaan met in de toelichting te vermelden b.v. aan twee der commissarissen wordt een bezoldiging van $f \mathrm{x}$ toegekend, aan de overige drie $f$ ij. Hieruit moge blijken dat de uitleg van een eenvoudige bepaling nog van betekenis kan zijn, in het midden latende of de commissie wel zou blijken gelijk te hebben, als er over de toepassing een rechtsgeding zou ontstaan.

Maar bovendien kennen wij problemen rond de commissarisbeloning naar aanleiding van de toepassing van de commissarissenbelasting. Heeft het vermeldingsvoorschrift uitsluitend betrekking op de commissarisbezoldiging krachtens de statuten? Zulks ongeacht andere bezoldigingen, door de onderneming van de persoon, die haar commissaris is? Dat moet men bij gebrek aan enig ander gegeven wel aannemen. Mogelijk moet men dan ook wel wat sceptisch staan tegenover de werking van deze bepaling.

Gezien hun omvang enerzijds en van een belangrijk gedeelte hunner de minder grote betekenis anderzijds moet de bespreking van de bepalingen omtrent de balans en de toelichting beperkt blijven tot kanttekeningen.

Het komt ons voor, dat de belangrijkste bepalingen die van artikel 12 zijn. Zij betreffen het verstrekken van gegevens over de deelnemingen. Van een begripsbepaling van deelnemingen heeft de commissie afgezien. $Z_{i j}$ stelt voor te bepalen in ieder geval als deelneming te beschouwen het houden van aandelen van een onderneming tot een nominale waarde van tenminste een vierde gedeelte van haar geplaatste kapitaal. Er worden voorschriften gegeven, welke verder gaan voor de meerderheidsdeelnemingen dan voor de overige deelnemingen, op grond onder meer van de macht van de onderneming, houdster van de meerderheid der aandelen (rechtstreeks of middellijk).

Ten aanzien van de deelnemingen wordt bepaald, dat omtrent de vermogenswaarde van de deelneming en de wijzigingen daarin tijdens het afgelopen boekjaar zo getrouw mogelijk inlichtingen worden verstrekt. De inlichtingen omtrent de wijzigingen in de vermogenswaarde worden gesplitst in die omtrent wijzigingen tengevolge van winst of verlies op deelnemingen en wijzigingen tengevolge van andere oorzaken.

Omtrent de meerderheidsdeelnemingen worden voorts alle gegevens verstrekt, die krachtens deze wet in de jaarrekening moeten voorkomen. Deze gegevens worden verstrekt hetzij in de vorm van afzonderlijke of samengevoegde jaarrekeningen van deze ondernemingen, hetzij in die van een geconsolideerde jaarrekening van de onderneming.

Of er van een deelneming sprake is bij minder dan een vierde van het geplaatste kapitaal dan wel van eenvoudige belegging is afhankelijk van de aard van het aandeelhouderschap. Enig criterium daarvoor stelt de commissie dan overigens niet.

Wel geeft zij zijdelings te kennen, dat zij eenheid van waarderingsgrondslagen 
van essentiële betekenis acht. $\mathrm{Zij}$ schrijft, dat de deelnemende onderneming, indien zij bij machte is die eenheid te bewerkstelligen, hiertoe moet overgaan. De onderneming zal wel altijd geacht worden die macht te bezitten ten aanzien van meerderheidsdeelnemingen. Omtrent de vraagstukken, die hier liggen, wanneer het om deelneming in buitenlandse ondernemingen gaat, laat de commissie zich niet uit.

Met de voorstellen van de commissie zal de geconsolideerde jaarrekening haar intrede in de Nederlandse wetgeving doen. Op de voorgestelde wijze doet zij dat dan evenwel zonder een enkel woord van toelichting. Zou het waar zijn, dat iedere toelichting op de vereisten, waaraan een geconsolideerde jaarrekening moet voldoen, kan worden gemist? Bovendien komt het ons voor, dat opheldering moet worden verkregen over de verhouding van twee der bepalingen, te weten dat omtrent de meerderheidsdeelnemingen alle gegevens verstrekt worden, die krachtens deze wet in de jaarrekening voorkomen enerzijds en anderzijds dat deze gegevens worden verstrekt b.v. in de vorm van een geconsolideerde jaarrekening.

In de geconsolideerde jaarrekening worden de door de wet voorgeschreven gegevens ten aanzien van de meerderheidsdeelnemingen niet gegeven. Ook niet wanneer de geconsolideerde jaarrekening van een toelichting zal zijn voorzien om de bezoldiging van commissarissen en de namen van houders van prioriteitsaandelen (waarover straks) te vermelden. Door met de geconsolideerde jaarrekening te - volstaan met een geconsolideerde jaarrekening, niet in haar beschouwingen heeft maakt naar dezelfde waarderingsgrondslagen, afzonderlijk. Laat ik volstaan met te wijzen op de compensatie van winsten en verliezen in de winst- en verliesrekening, die de geconsolideerde jaarrekening eigen is. Soms bevordert die compensatie het inzicht, soms belemmert ze die.

Jammer, dat de commissie de strijdvraag of de deelnemende onderneming kan volstaan met een geconsolideerde jaarrekening niet in haar beschouwingen heeft betrokken. Er wordt veel uitgekeken naar verdere uitingen op dit punt. Met name het woordje "voorts" in artikel 12 lid 3 doet weer overhellen naar de mening, dat de deelnemende onderneming tenminste een jaarrekening en wel haar wettige jaarrekening moet maken met de deelnemingen daarop vermeld. Tenzij de constructie der commissie, dat ook de toelichting onderdeel van de jaarrekening is, de mogelijkheid zou bieden te besluiten, dat een geconsolideerde jaarrekening met toelichting omtrent de deelnemingen voldoende zou zijn. Maar welke toelichtingen zouden dat dan moeten zijn? De vermogenswaarden en hun wijzigingen? Zulks naast een geconsolideerde jaarrekening?

De tweede belangrijke rubriek betreft naar ons oordeel de voorzieningen. De toelichting, welke de commissie op de door haar voorgestelde bepalingen geeft, is uitvoeriger ter zake van de uitzondering, welke is opgenomen voor de banken, dan voor het verschijnsel in het algemeen. Dat is jammer, omdat de indruk wel eens gezegd is gewekt te zijn, dat het probleem van de stille en geheime reserves moet worden herbenoemd als dat der stille en geheime voorzieningen.

Het is niet duidelijk of de commissie bedoelt en in staat is, onderscheid te maken tussen voorzieningen tegen bepaalde risico's en voorzieningen tegen verplichtingen, waarvan de omvang ten tijde van de balans nog niet nauwkeurig bekend is. Zij noemt ze in één adem in artikel 20 lid 1 en als daar dan in staat, dat die voorzieningen afzonderlijk moeten worden vermeld, dan is dat onduidelijk. 
Moet de groep voorzieningen afzonderlijk worden vermeld of elke voorziening afzonderlijk? Dan wel de gezamenlijke voorzieningen tegen bepaalde risico's afzonderlijk en die tegen niet vaststaande verplichtingen eveneens gezamenlijk afzonderlijk?

Over de voorziening voor belastingverplichtingen zijn de uitlatingen van de commissie ook niet zo duidelijk als gewenst zou zijn.

In artikel 21 wordt de afzonderlijke vermelding van belastingschulden voorgeschreven, terwijl in artikel 20 lid 3 de afzonderlijke vermelding van de voorziening voor belastingverplichtingen, welke na het boekjaar kunnen ontstaan, wordt vereist. Men zou moeten aannemen, dat met de belastingschulden worden bedoeld de belastingverplichtingen, welke voor het einde van het boekjaar zijn ontstaan b.v. doordat de aanslag is opgelegd; en de voorzieningen dan dienen voor al datgene, waar men als verplichting mee moet rekenen, waar zulks nog niet het geval is. Wat nu te denken van de bepaling in artikel 26 ter zake van de specificatie van de winst- en verliesrekening, die afzonderlijke vermelding voorschrijft van de voorziening voor belastingen. Hoewel de commissie geen toelichting ten deze geeft, moet toch worden aangenomen, dat hier bedoeld wordt het bedrag der naar de winst geheven belastingen, dat ten laste van de winst- en verliesrekening is gebracht. Ten dele kan dat bedrag dan bestaan uit een belastingschuld volgens artikel 21 , welke al of niet voor het einde van het boekjaar reeds is voldaan en een voorziening voor een te verwachten aanslag over het verstreken jaar alsmede voorzieningen voor z.g. latente belastingverhoudingen. Hier had in de toelichting wel iets meer van kunnen worden gezegd. Ook moet toch worden aangenomen, dat het niet de bedoeling is voor te schrijven een voorziening voor te betalen omzetbelasting, zo die voorkomt, afzonderlijk in de winst- en verliesrekening op te nemen, daarlatende of in een zeer bijzonder geval zo een afzonderlijke vermelding wel nodig zou kunnen zijn.

Voorts is opmerkelijk, dat de commissie zich niet uitlaat en mitsdien geen eisen stelt terzake van de vermelding van de afloop van voorzieningen. Is het stilzwijgend toevoegen van reserves aan de winst een zaak, waar bestuurders van ondernemingen zich nu wel algemeen niet vrij in voelen, het opnemen in de winst van een vrijgevallen voorziening uit een vorige periode wordt nog wel anders beoordeeld. Zeker, men kan dan wijzen op het vereiste, dat de jaarrekening in staat moet stellen tot een verantwoord oordeel over de rentabiliteit van de onderneming te komen, maar staat het zo vast, dat die vrijgevallen voorziening niet zou behoren in het beeld van de rentabiliteit? Mogelijk zou ze dan wel tot de buitengewone baten gerekend moeten worden maar ook daarover vinden we noch bij de voorzieningen, noch bij de buitengewone baten en lasten enige toelichting. Hier ligt mogelijk het zwakste punt van het voorstel, voor zover het op de detaillering van de jaarrekening betrekking heeft.

Tot slechts enkele korte opmerkingen bij de overige bepalingen in dit hoofdstuk zullen wij ons nu beperken.

Het valt op, dat in artikel 11 ten aanzien van de immateriële activa in het voorontwerp van wet een waarderingsregel is gegeven. Blijkens de toelichting is dit gebeurd om te voorkomen, dat een onderneming door deze waarden op te voeren, een te gunstig beeld van haar financiële positie geeft. Met die strekking kan men vrede hebben maar wat is de betekenis van de ontworpen wetstekst? „De immateriële activa worden op de balans opgenomen tot het bedrag van de 
uitgaven, die de onderneming zich daarvoor heeft getroost, verminderd met het bedrag der afschrijvingen."

Dat zou betekenen, dat die activa op de balans moeten worden vermeld, ook als ze jaarlijks geheel worden afgeschreven. Wij kunnen ons niet voorstellen, dat de commissie, mede gezien haar toelichting, wat de gevaren van activering betreft, zou bedoelen een waarderingssysteem zonder activering van immateriële activa niet geschikt te achten om aan de algemene vereisten, waaraan de jaarrekening moet voldoen, recht te doen wedervaren.

Bovendien moeten wij opmerken, dat in artikel 11 lid 1 wel wordt gesproken van afschrijving op immateriële activa, maar dat in artikel 26 (voorschrift detaillering winst- en verliesrekening) slechts wordt vermeld: afschrijving op duurzame goederen. Vallen daar de immateriële activa onder? Zijn dat wel goederen?

Dat de oprichtersbewijzen en winstbewijzen e.d., zo ze er zijn, in de jaarrekening moeten worden vermeld (artikel 18) achten wij een doelmatig voorschrift. Maar waarom daarvan dan de aantallen moeten worden medegedeeld, is ons onduidelijk. Welke rechten die uitstaande stukken hebben, komt ons voor een doelmatiger inlichting te zijn.

Het voorschrift te vermelden voor welke schulden zekerheid is gesteld en in welke vorm dit is geschied, alsmede ten aanzien van welke schulden de onderneming zich heeft verbonden haar goederen niet te bezwaren (artikel 19 lid 2) is zeker van belang.

Maar het voorschrift omvat niet de vermelding van gepriviligeerde schulden krachtens de wet. Een oordeel over de positie der concurrente schulden zal op die wijze dan ook niet ten volle kunnen worden verkregen; onder bepaalde omstandigheden zelfs in het geheel niet.

Het voorgestelde onder artikel 17 lid 1 sub d (mededeling van): de namen van de houders van (populair uitgedrukt) de prioriteitsaandelen, alsmede de nominale waarde van de aandelen van deze soort, die elk hunner houdt, moeten wij een ondergeschoven kind achten. Het hoofdstuk II zou bepalingen bevatten ter uitwerking van de algemene voorschriften ten aanzien van de jaarrekening. Van welke betekenis men ook de kennis acht, die het gereleveerde voorschrift behoort te verschaffen, dat voorschrift behoort niet in dit hoofdstuk. Het zou in de algemene bepalingen thuishoren, zoals de vermelding van de bezoldiging van commissarissen, die ook in dat hoofdstuk is voorgeschreven.

In de toelichting bij het voorschrift van artikel 17 lid 1 sub d komt een opmerking voor van een minderheid in de commissie, welke bezwaar heeft tegen de voorgestelde bepaling, welke opvallend moet worden genoemd. Er staat, dat die leden zich afvragen, of de bepaling in de voorgestelde vorm altijd uitvoerbaar zal zijn (bij voorbeeld indien de onder $1 \mathrm{~d}$ bedoelde aandelen aan toonder luiden).

Wat moeten we ons voorstellen bij prioriteitsaandelen aan toonder? Dat zij vrij overdraagbaar zijn? Dat de meerderheid, die haar bijzondere rechten kan doen gelden, voor de meest biedende te koop kan zijn? Men kan toch niet anders menen, dan dat een dergelijke situatie zo zeer tot de ontoelaatbare zou moeten worden gerekend, dat er geen argument aan kan worden ontleend.

Het voorgestelde in artikel $\mathbf{2 2}$ is zo interessant, dat wij niet mogen nalaten het te vermelden. De bepaling luidt:

Indien de onderneming zich heeft verbonden tot de voldoening van voor haar belangrijke financiële verplichtingen gedurende een aantal jaren, zoals tengevolge 
van erfpacht, opstal, huur, pacht, koop op afbetaling, bevrachting en licentieovereenkomsten, wordt van deze verplichtingen, hetzij onder de schulden, hetzij afzonderlijk melding gemaakt.

Hiermede wordt dan een beslissing gegeven in het vraagstuk van het al dan niet verwerken van obligo's in de verslaglegging, onderwerp van een subcommissie van de C.A.B., van het N.I.v.A., welke daarover in 1956 rapport uitbracht (De Accountant, 62e jaargang No. 6).

Opgemerkt moet worden, dat de commissie tot onderwerp van dit voorschrift rekent de langjarige verbintenissen. Omtrent de korter lopende als voor-inkopen en voor-verkopen van goederen, termijncontracten in goederen en in vreemde valuta, spreekt zij niet; zo ook niet van voor derden geopende onherroepelijke credieten.

Van de bepalingen omtrent de winst- en verliesrekening en de toelichting is de eerste bijzonderheid, dat het er maar twee zijn (artikelen 25 en 26). Dat is natuurlijk wel een groot verschil met de huidige wettelijke bepalingen, die geen specifieke voorschriften voor de resultatenrekening kennen; maar het verschil met de balansvoorschriften blijft markant.

De commissie oordeelt, dat de omzet uiteraard een van de belangrijkste gegevens voor de beoordeling van de financiële positie van een bedrijf is. Een uitspraak, die wij voor rekening van de commissie willen laten. Maar met dat oordeel over de betekenis van het gegeven van de omzet, heeft de commissie toch afgezien van een voorstel vermelding van het absolute getal van de omzet in de jaarrekening voor te schrijven. Meent de onderneming de absolute cijfers niet te kunnen overleggen, dan zal zij vergelijkende cijfers ten opzichte van het vorige jaar moeten vermelden.

De overige bepaling omtrent de winst- en verliesrekening is een specificatievoorschrift.

\section{De publiciteit}

In het stelsel van de publicatieplicht der naamloze vennootschappen heeft de commissie geen wijziging voorgesteld. De publicatieplicht der naamloze vennootschappen blijft beperkt tot dezulken, die aandelen (of certificaten) aan toonder hebben uitstaan van tenminste $f 250.000,-$. Niet alleen wordt dus voorgesteld het bedrag van $f 50.000$,- genoemd in art. $42 \mathrm{c}$ W.v.K. te verhogen; ook wordt niet de mogelijkheid van aandelen aan toonder (of certificaten) volgens de statuten meer als criterium genomen, maar vervangen door het uitstaande bedrag dier stukken. Beide detailwijzigingen kan men verbeteringen achten.

Omtrent het jaarverslag worden geen voorstellen gedaan.

Ook onder de voorstellen van de commissie kan desgewenst het verslag mondeling ter vergadering worden gegeven.

\section{De sanctie}

De commissie heeft zich tenslotte gesteld gezien voor de vraag hoe de nakoming van de gestelde normen kan worden gewaarborgd. $\mathrm{Zij}$ wijst er terecht op, dat de controle op de naleving der voorschriften omtrent de inhoud der jaarstukken in de eerste plaats berust bij hen, aan wie de jaarstukken krachtens de wet dienen 
te worden aangeboden, bij de aandeelhouders alsmede bij de commissarissen, dan wel de leden van een (coöperatieve) vereniging.

De commissie verwacht, dat in vele van de kleine en middelgrote ondernemingen daarmede voldoende zal worden bereikt, omdat de kapitaalverschaffers daar nog genoeg met het bedrijf plegen mee te leven en de onderneming ook overzichtelijk genoeg is. Zij merkt op, dat ook in die gevallen de algemene vergadering van aandeelhouders van haar recht een accountant te benoemen gebruik kan maken.

Voor de zogenaamde open naamloze vennootschap en de grote, besloten N.V. (geplaatst kapitaal van $f 500.000$,- of meer), alsmede voor de grote coöperatieve vereniging, stelt de commissie voor de benoeming van een accountant verplicht te stellen. Deze deskundige zal dan uit de kring der Register-accountants moeten worden gekozen. Hij zal bij zijn controle tevens moeten nagaan of aan de voorschriften van de Wet op de jaarrekening van ondernemingen is voldaan.

De huidige bepaling (art. 42a W.v.K.) dat de algemene vergadering van aandeelhouders de bezoldiging van de accountant bepaalt, wil de commissie zien vervallen. $\mathrm{Z}_{\mathrm{ij}}$ meent, dat het meer op de weg van het bestuur ligt zijn bezoldiging met de accountant overeen te komen. Dit is zeker een aanpassing aan de praktijk.

Deze wijziging zal mogelijk tot gevolg hebben, dat de benoeming van de accountant door de algemene vergadering van aandeelhouders, die in Nederland weinig voorkomt, meer in gebruik zal komen. Wij menen dat zulks wenselijk zou zijn.

Indien de algemene vergadering van aandeelhouders niet van haar recht een accountant te benoemen heeft gebruik gemaakt, zullen de commissarissen bevoegd blijven zulk een benoeming te doen, doch zij zullen daartoe zijn verplicht bij de open en bij de grote, besloten vennootschap.

Hoezeer dit een en ander ook van belang mag zijn voor de accountant, op dit punt zijn de voorstellen van de commissie in grote mate in overeenstemming met wat daarvan wel allerwege werd verwacht. Een geheel nieuw geluid doet de commissie horen in haar voorstellen voor de sanctie op het niet naleven van de voorschriften van de Wet op de jaarrekening van ondernemingen.

De vraag of die voorschriften wel zijn nageleefd kan door iedere belanghebbende worden voorgelegd aan de ondernemingskamer van het gerechtshof te Amsterdam. Ook de procureur-generaal bij dat gerechtshof zal daartoe bevoegd zijn. Tegen arresten van de ondernemingskamer zal slechts beroep in cassatie openstaan.

Indien de ondernemingskamer van oordeel is, dat de bedoelde voorschriften niet of niet ten volle zijn nageleefd, beveelt zij de onderneming haar jaarrekening in te richten volgens bij dat bevel te geven aanwijzigingen. Een strafsanctie is de stok achter de deur voor de niet nakoming van dat bevel.

Wanneer dus het ondernemingsbestuur zijn verplichtingen ingevolge de Wet op de jaarrekening van ondernemingen niet nakomt, wordt hem het recht, de jaarrekening te maken binnen de voorschriften van de wet, uit handen genomen. Dat bestuur wordt dan bij rechterlijk vonnis bevolen de jaarrekening te maken overeenkomstig de aanwijzingen van de rechter.

De commissie motiveert uitvoerig haar keuze tussen de sanctie door middel van de strafrechter, door een administratief overheidsorgaan dan wel door de burgerlijke rechter. Haar voorkeur voor een civielrechtelijk college is gegrond op verwachte voordelen, waarvan de belangrijkste in de aanvang van dit artikel 
reeds zijn genoemd. Het spreekt vanzelf, dat het bepalende element blijft of het ontworpen stelsel goed zal werken. Er is veel reden om daarvan goede verwachtingen te hebben. Slechts op uitzonderingen na zullen de besturen van ondernemingen duidelijke voorschriften vanwege de wettige overheid nakomen. Het zijn uitsluitend die uitzonderingen, waartegen een machtsmiddel onvermijdelijk is. Hun wordt het eigen recht uit handen genomen. Hun wordt bevolen door deskundige rechters, hoe hun verslaggeving, zo nodig tot in details, moet zijn.

Men moet verwachten, dat de sanctie niet in grote frequentie zal worden gehanteerd. Zou dat dan komen, omdat belanghebbenden de kosten van de civiele procedure er niet voor overhebben; welnu, dan hoeft er niet van een ernstig tekort in maatschappelijk opzicht te worden gesproken. En zal het slechts zelden tot toepassing komen een gevolg zijn van het allerwege voldoende naleven van de gegeven voorschriften, dan zal dat een parel aan de kroon op het werk van deze commissie zijn. Dan zal zij de Nederlandse gemeenschap in een moeilijke aangelegenheid een vruchtbare dienst hebben bewezen.

Wij houden het daar op. 